NASA Technical Memorandum 107653

$$
\begin{array}{r}
N-05 \\
1519 \\
13
\end{array}
$$

\title{
AN ANALYTICAL AND EXPERIMENTAL INVESTIGATION OF FLUTTER SUPPRESSION VIA PIEZOELECTRIC ACTUATION
}

Jennifer Heeg

July 1992

(NASA-TM-107653) AN ANALYTICAL AND

$N 92-31174$ EXPERIMENTAL INVESTIGATION DF

FLUTTER SUPPRESSION VIA

IEZOFLECTRIC ACTUATION (NASA)

Unclas

$13 \mathrm{p}$

G3/05 0115119

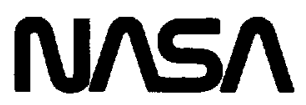

National Aeronautics and

Space Administration

Langley Research Center

Hampton, Virginia 23665-5225 


\title{
AN ANALYTICAL AND EXPERIMENTAL INVESTIGATION OF FLUTTER SUPPRESSION VIA PIEZOELECTRIC ACTUATION
}

\author{
Jennifer Heeg \\ NASA Langley Research Center \\ Hampton, VA 23665
}

\begin{abstract}
The objective of this research was to analytically and experimentally study the capabilities of adaptive material plate actuators for suppressing flutter. Piezoelectrics are materials which are characterized by their ability to produce voltage when subjected to a mechanical strain. The converse piezoelectric effect can be utilized to actuate a structure by applying a voltage. For this investigation, a two degree of freedom wind tunnel model was designed, analyzed and tested. The model consisted of a rigid wing and a flexible mount system which permitted translational and rotational degrees of freedom. Actuators, made of piezzoelectric material were afixed to leaf springs of the mount system. Command signals, applied to the piezoelectric actuators, exerted control over the closed loop damping and stiffness properties of the leaf springs. A mathematical aeroservoelastic model was constructed using finite element methods, laminated plate theory, and aeroelastic analysis tools. Plant characteristics were determined from this model and verified by open loop experimental tests. A flutter suppression control law was designed, implemented on a digital control computer and tested to conditions $20 \%$ above the passive flutter speed of the model. The experimental results represent the first time that adaptive materials have been used to actively suppress flutter. It demonstrates that small, carefullyplaced actuating plates can be used effectively to control aeroelastic response.
\end{abstract}

\section{INTRODUCTION}

Flutter, $3-$ interaction between the structural dynamic and the a amic characteristics of an aircraft causing diverge... nd destructive oscillations of motion, has been observed and documented since the era of controlled flight began. Historically, passive solutions such as increasing structural stiffness, mass balancing or modifying geometry have been used to prevent this hazardous phenomenon. These approaches result in increased weight and cost and decreased performance. During the past twenty years, there has been considerable research to develop active flutter suppression concepts which use conventional aerodynamic control surfaces. $[1,2,3,4,5]$ An active control approach eliminates most of the weight and performance penalties associated with the passive approach and additionally provides flexibility in that the control law could be varied with configuration or flight condition. Active flutter suppression is not yet a common practice in today's commercial or military aircraft due to several concerns. Flutter is generally of a catastrophic nature, therefore a failure of the system could affect flight safety. As a result, system redundancy, reliability and maintainability are critical issues. To a lesser extent, the control surface authority available to maneuver the aircraft with the simultaneous implementation of active flutter suppression is also a concern. To alleviate these concerns, altematives to utilizing the aerodynamic control surfaces for active flutter suppression are being studied.

The use of secondary controllers made of adaptive material is one such concept. There are several classifications of adaptive materials; the present study focused exclusively on the use of piezoelectric materials. Piezoelectricity is the ability of a material to develop an electrical charge when subjected to a mechanical strain and vice versa. Results available from aeroelastic applications of piezoelectric materials are very limited. Static aeroelasticity has been the subject of investigations by Ehlers and Weisshaar. $[6,7,8]$ They conducted analytical studies on laminated composite wings with embedded actuators, looking at pure torsional and bending deformations. They reported that through feedback to embedded adaptive material layers, the divergence speed is altered, implying also that lift effectiveness is influenced. The augmentation or replacement of conventional aerodynamic control surfaces with strain actuation for aeroelastic control has been the focus of an analytical investigation of a typical section by Lazarus, Crawley and Lin. ${ }^{[9]}$ They found that strain actuation via piezoelectric elements may provide a viable and effective altemative to articulated control surfaces for controlling aeroelastic response. Investigation of flutter suppression for lifting surfaces and panels has been done by Scott. ${ }^{[10]}$ This analytical study considered controlling flutter at supersonic speeds using full state feedback.

The purpose of the present study was to investigate flutter suppression using piezoelectric plates as actuators. Results from analyses and experiments demonstrating this technology are presented. This paper includes: discussion of piezoelectric materials; details concerning the experimental model, the wind tunnel facilities and the testing procedures; details concerning the analytical model 
development, the analysis results and the control law design; and the experimental results and comparison with analytical predictions. A more in-depth presentation of the material contained in this study may be found in reference 11.

\section{PIEZOELECTRIC MATERIALS}

A material which, when subjected to a mechanical load, accumulates an electrical charge is said to have piezoelectric properties. Many naturally-occuring crystals have piezoelectric capabilities but their non-uniform properties encouraged research into manufacturing materials which would produce electromechanical coupling. Certain polymers and ceramics consist of crystalline subdomains which are bipolar in nature. Piezoelectric properties can be induced in these materials by applying a large electrical field across them. This induces an orientation of the dipoles such that the positive and negative poles of the individual domains are aligned with the applied field, denoted the 3-direction, (figure 1). The orientation remains after the inducing field is removed. In order to subsequently deform the material, a smaller voltage is applied through electrodes on opposite faces of the material. The most common configuration is to place the electrodes on the faces parallel to the poled axis and to apply the voltage in the same direction as the original inducing field. As shown in figure 2 , the material deforms both through the thickness, denoted the $d_{33}$ effect, ( voltage in the 3-direction and displacement in the 3-direction), and in the in-plane directions, denoted the $\mathrm{d}_{31}$, (voltage in the 3-direction and displacement in the 1direction). Applying a voltage through the thickness in one direction induces in-plane expansion; applying it in the other induces in-plane contraction.

Piezoelectric plates can be configured in different ways to accentuate the displacements or forces being generated. The in-plane expansion and contraction of adaptive materials may be utilized by bonding actuating plates to either side of a center shim, (figure 3). One is expanded while the other is contracted resulting in a bending displacement much greater than the length deformation of either of the two layers. This configuration, which takes

advantage of the Poisson-like $d_{31}$ effect, is referred to as a bimorph or a bender element. It will serve as the primary actuator mechanization for the investigation described herein.

Lead Zirconate Titanate (PZT), a piezoceramic, was chosen for this investigation. The material properties for PZT are given in table 1. The material properties have been treated in this work with linear relationships. This assumption is valid for low applied voltages and small deformations, Nonlinearities and nonidealities of these materials have been well-documented by references 6,7 and 9.

\section{EXPERIMENTAL_APPARATUS}

\section{WIND TUNNEL}

The piezoelectric flutter suppression model was tested in the Langley Research Center Flutter Research and Experiment Device (FRED). The FRED is an open circuit table top wind tunnel with a maximum operating velocity of 85 miles per hour ( approximately 1500 inches per second ). The test section is six inches by six inches, and is constructed of plexiglass for model viewing. The air is pulled through the tunnel by a 2 horsepower motor and smoothed by a single honeycomb screen at the beginning of the contraction duct. Models are mounted from the removable ceiling of the test section. Figure 4 shows the test article suspended from the test section ceiling.

\section{TEST ARTICLE}

The piezoelectric flutter suppression wind tunnel model consists of four integral components: a flexible mount system, a rigid wing, piezoelectric plate actuators and a strain gage bridge. There were three driving factors in the test article design: the model had to flutter within the wind tunnel envelope; had to fit inside the wind tunnel with certain margins of safety; and had to have flat surfaces on which piezoelectric actuating plates could be mounted. Therefore, a rigid wing was designed with a flexible mount system that would reside outside of the wind tunnel. The flexible mount system provided two degrees of freedom: plunge (out-of-plane translation) and pitch ( rotation about the wing pitch axis). With the rigid wing attached to the flexible mount system, the two degrees of freedom became coupled by virtue of the wing mass distribution.

The mount system suspended the wing by two pins through slots in the test section ceiling and provided the plunging and pitching freedoms by virtue of separate spring tine mechanisms. The plunge mechanism consists of two spring steel plates or tines separated by .75 inches and clamped at both ends. The pitch mechanism is a single spring tine connected to the wing at the leading edge and at the .2353 chord location, where there is a bearing-like mechanism which allows for free rotation.

The wing consists of three sections. The primary wing structure is formed from one eighth inch thick aluminum. It has a chord of 2 inches, with the pitch pivot at the midchord. A balsa wood extension overlays the aft half of the primary structure and extends the chord length to 4.25 inches. The trailing edge of this section was coated with aluminum to provide a mass ballast. All three sections extend the full span of the wing, which is 4 inches. Model characteristics are presented in table 2.

Piezoelectric ceramic plates were installed near the root of one of the steel plunge spring tines to actuate the test article. Two plates, $1-1 / 2$ inches long and 1 inch wide, were bonded to opposite sides of the plunge spring tine, 
with their poles both oriented towards the steel, to form an actuator. The .0075 inch thick plates were electrically isolated from the steel by the bonding layers. Small copper tabs afixed beneath the plates during the bonding process served as the means of applying voltages to the bonded-side electrodes, (figure 5).

A strain gage bridge was mounted near the base of one of the spring tines, with two gages on either side of the tine. The gages were configured to measure the cantilever bending strain and were used as the feedback signal for the controller.

\section{DIGITAL CONTROLLER}

The control laws were implemented using a personal computer, with a 80386 processor and 80387 co-processor running a real time Unix operating system. The control laws are programmed in the C-language and use floating point arithmetic for all control law calculations. The data acquisition system uses 12 bit analog-to-digital converters. Additional details of the controller and data acquisition system can be found in Reference 12 .

\section{ADDITLONAL_INSTRUMENTATION}

Aside from the strain gage, there were two sensor systems in use: a linear accelerometer and a hot wire anemometer. The accelerometer was used in system identification experiments; it served as a roving measurement, being placed where applicable for different experiments. During zero airspeed testing, it was located on the wing, however, during flutter testing it was installed on the clamping block of the mount system. A Kurz $443 \mathrm{M}$ air velocity meter, a hot wire anemometer, provided visual readouts of the test section airspeed. The probe was inserted into the flow just behind the model in the test section. Airspeed was measured by removing the model from the tunnel to eliminate blockage and the influence of wing oscillations on the reading.

An Apex Microtechnology P83A operational amplifier was used to boost the input voltage to the piezoelectric actuators. The signal source or input voltage was amplified by a factor of 25 , with a limit on the output voltage equal to the power supply voltage, which in this experiment was $+/-80$ volts.

\section{ANALYSES}

The analytical model was developed incorporating the aeroservoelastic equations of motion, a model of the control computer dynamics and experimentally-determined correction factors. Analyses were performed utilizing the aeroservoelastic equations of motion. Results from system identification tests, which include natural frequencies, structural dampings, and scale factors for the actuator and the sensors, were incorporated into the aeroservoelastic equations of motion prior to the open loop analysis. Aeroservoelastic equations of motion based on Lagrange's energy equations represent a summation of forces which include the inertial, dissipation, and internal restoring forces, and the reduced-frequency dependent aerodynamic forces due to the structural motions. Classical techniques available to the aeroelastic community were utilized to develop the equations.

\section{MODEL DESIGN}

Structural Model A finite element model of the wind tunnel wing and the two degree of freedom mount system, (figure 6), was constructed and analyzed. The wing was modeled with solid elements and concentrated masses. The spring tines were modeled with plate elements. A torsional spring was added at the pivot point to better represent the experimentally-determined pitch frequency. The primary purpose of the finite element model was to generate the structural mass and stiffness matrices. The model was also utilized to perform parametric studies for the design of the mass ballast and to determine the placement of the actuating plates necessary to obtain the maximum control effect.

A normal mode analysis was performed to generate the two important natural frequencies and mode shapes of the model. The first mode, designated plunge due to the dominance of translational motion, was predicted at a frequency of $7.8 \mathrm{~Hz}$. The second mode, which is characterized by the pitching of the wing relative to the mount system, has a natural frequency of $10.9 \mathrm{~Hz}$.

Aerodynamic Model Unsteady aerodynamics were calculated using the Doublet-Lattice Method ${ }^{[13]}$ as implemented in the Aeroelastic Vehicle Analysis (AVA) system of computer codes. AVA uses the modal displacement vectors to calculate the generalized aerodynamic forces (GAFs) at discrete reduced frequencies. The program output is a table for each reduced frequency, where the columns of the table correspond to modal deflections, and the rows correspond to modal pressures or forces. The aerodynamic model has 5 chordwise boxes and 10 spanwise boxes for a total of 50. The GAFs were calculated at Mach .05 for 8 values of reduced frequency ranging from .001 to 2.0 .

\section{OPEN LOOP AEROELASTIC ANALYSIS}

The structural model and the aerodynamic model were combined to form the open loop aeroelastic equations of motion. Flutter analyses were conducted by analyzing this model for sea level density using the STABCAR computer code. ${ }^{[14]}$ The velocity root locus plot of figure 7 shows the open loop flutter characteristics. The plot traces the eigenvalues of the system as the airspeed is increased. The imaginary axis represents the point of neutral stability or zero damping, where, theoretically, responses will neither converge nor diverge. Flutter, defined as an oscillatory divergence, is represented on a root locus plot by an eigenvalue crossing this axis into the right half plane. 
Figure 7 shows the coalescent behavior of the plunge and pitch modes for sea level density as the airspeed increases. The frequencies of the two modes migrate towards one another as the aerodynamics couple the their motion. When the frequencies are close together, the modes interact with one another and the system is driven unstable, shown by the lower frequency mode eigenvalue crossing into the right half plane. Flutter is predicted to occur at a velocity of 560 inches per second and at a frequency of $9.1 \mathrm{~Hz}$.

\section{STATE SPACE_AEROSERYOELASTIC EQUATIONS OF MOTION}

The formulation of a state space aeroservoelastic model requires that the piezoelectric control forces be combined with the aeroelastic equations of motion described above.

The control forces from the piezoelectric elements were developed utilizing laminated plate theory in conjunction with Lagrange's energy method. The modeling of piezoelectrical systems requires consideration of both mechanical and electrical behavior. Coupling between mechanical stresses and electrical fields is analytically represented by constitutive relationships which contain both the electrical quantities and the mechanical quantities. This relationship is utilized in expressing the potential energy-- the presence of the strain due to electrical energy generates a term which is not traditionally observed in the mechanical potential energy expression. The control force is calculated using a finite difference program.

The aerodynamic forces within the aeroelastic equations of motion produced by the Doublet-Lattice code are transcendental functions of reduced frequency. To incorporate them into the state space equations of motion, they must be approximated by rational functions of the Laplace variable, s. ${ }^{[15]}$ The Integration of Structures, Aerodynamics and Controls (ISAC) system of cades ${ }^{[16]}$ was used to generate the resultant s-plane GAFs.

The development of the first order state equations of motion was accomplished using Matrix X, a commercially-available software package from Integrated Systems Incorporated. [17] These continuous system matrices were then discretized using a $20 \mathrm{~Hz}$ sample rate. A block diagram of generic form, describing the closed loop system is presented in figure 8 .

\section{MODELING THE CONTROL COMPUTER DYNAMICS}

Illustrated in figure 9 for a gain feedback control law, the control computer introduces its own dynamics into the feedback path. The digital controller implementation scheme shifts the output data by one sample and applies a zero order hold. The frequency response of the digital controller is different for different sample rates. By using a sample rate which provides the correct amount of phase shift near the frequency of control interest allows the system to simulate analog derivative feedback, despite having only displacement measurements. ${ }^{[18]}$ The current control law utilizes these dynamics of the implementation scheme, requiring only gain feedback. Figure 9 shows that for a $20 \mathrm{~Hz}$ sample rate, the phase is -270 degrees, or +90 degrees at the Nyquist frequency, $10 \mathrm{~Hz}$. Thus, the phase characteristics simulate a derivative near the anticipated flutter frequency, which is the frequency of
interest for control.

\section{CONTROL LAW DESIGN \& CLOSED LOOP ANALYSIS}

The control law design requirement for the current study was to suppress flutter for the largest velocity possible. Due to the simplicity of both the design objective and the test article, the aeroelastic phenomenon was controllable through a single input / single output control law. Gain feedback ${ }^{[19]}$ utilizing the dynamics of the discretization process was employed. The strain-proportional voltage was the input to the control law. The implementable feedback gain was limited to $+/-33$ due to a voltage limitation of the amplifier driving the piezoelectric plates.

Control law design is traditionally performed in the continuous domain, however because the control law computer discretization was an integral part of this design, the discrete domain model was utilized in this investigation. On a diagram of discrete system eigenvalues, the stability condition corresponds to the location of the roots relative to the unit circle. Roots located outside of the unit circle correspond to instabilities. That is, the imaginary axis of the continuous complex plane, maps to the unit circle of the discrete complex plane.

Design models were constructed from the aeroservoelastic equations of motion at several velocities. The model representing the system at 580 inches per second, a condition above the flutter prediction, was the initial design model. A discrete gain root locus, constructed by varying the gain from 0 to 120 is shown in figure 10 . Each eigenvalue trace of the discretized system begins at the open loop system values which correspond to a feedback gain of zero. One pair of roots shown in figure 10 is unstable for the open loop case as this velocity corresponds to a condition above open loop flutter. The flutter mode eigenvalues stabilize for small feedback gains; they migrate inside the unit circle almost immediately. As the gain increased, the eigenvalues continue to migrate in the unit circle for feedback gains up to 108 , where one destabilized again.

The stability criterion can be expressed as a limit on the magnitude of the eigenvalues. The magnitude of the largest eigenvalue must be less than 1.0 for the system to be stable. Figure 11 shows the value of the maximum magnitude of the eigenvalues plotted against feedback gain. The design model, linearized at 580 inches per second, is shown to be stable for gains between 14 and 108. This model, however, represents the system at only one airspeed. The same figure shows the variation with 
gain for several airspeeds. For 1 inch per second airflow, the model was stable for all gains below 104. The maximum airspeed for which gain feedback stabilized the system was found to be 1300 inches per second. As indicated in the figure, gains of between 103 and 108 stabilized the system at this airspeed. If physically attainable and no stability margins are required, 103 is the optimal gain. Practical limitations on the gain as described previously, however, did not allow a gain of this magnitude to be implemented.

Using the largest allowable feedback gain, 33, a velocity root locus was constructed. Figure 12 shows the traces of the eigenvalues as the velocity is increased from 0 to 700 . As with the gain root locus, a stable system has eigenvalues all lying within the unit circle. The figure shows the potential flutter mode migrating towards the unit circle for increasing velocities. The root crosses the stability boundary, predicting closed loop flutter at 648 inches per second. The previous graph, (figure 11), shows the variation of maximum eigenvalue magnitude as a function of gain for this velocity. The influence of increasing velocity can also be seen on this graph by examining the dashed vertical line representing a feedback gain of 33. For a velocity of 648 inches per second, the eigenvalue trace intersects the stability boundary. Recall that this is the predicted closed loop flutter speed. For velocities greater than the closed loop flutter speed, there is a substantially increased magnitude of instability. This is illustrated by the data corresponding to a velocity of 1300 inches per second.

\section{EXPERIMENTS}

Experimental results from bench tests and wind tunnel tests are presented in this section. Bench tests provided zero airspeed system identification results. The wind tunnel results to be discussed include system identification and flutter testing. Open and closed loop flutter tests were conducted and the results are compared to one another as well as to analytical predictions.

\section{SYSTEM IDENTIEICATION TESTING}

System identification testing was performed using several techniques to extract modal frequencies, dampings, transfer functions and general system behavior. Impulse response functions of the accelerometer were generated by hammer taps. A second technique, employed to obtain a more dramatic response from the pitch mode was to pluck the spring tine and record the free decay data.

Impulse Tests Hammer taps to produce impulsive acceleration responses were used at zero airspeed to extract the undamped natural frequencies. Figure 13 shows time histories of hammer input and accelerometer response and the normalized power spectral density of the acceleration response due to the hammer input. The power spectral density indicates that the natural frequencies of the final configuration are 7.9 and $11.1 \mathrm{~Hz}$. The structural damping of the plunge mode was also determined from this data by taking the ratio of the frequency width of the peak at the half amplitude and the natural frequency. The damping ratio is half of this value, .017 .

This identification method could be used only at zero airspeed because the wing could not be directly accessed while in the wind tunnel. Additionally, the amount of disturbance introduced to the flow by the presence of the accelerometer and its lead wire drastically altered the aerodynamic behavior.

Eree Decay Tests Free decay tests were used to extract the open loop damping of the pitch mode and to compare the open and closed loop dampings of the plunge mode. This free decay technique was effective at low airspeeds, where the plucking did not perturb the model enough to induce large oscillations.

The first set of tests were conducted by constraining the model in plunge and then plucking the pitch spring tine. This method was utilized because the impulse response testing failed to extract data suitable for determining the pitch mode damping. Random input tests could not be used as there was no actuator for this degree of freedom. No transfer functions between the input and output can be derived using this method because the input signal can not be recorded. The usefulness of this test was in the determination of the pitch mode damping and frequency. A resultant time history from the free decay testing is presented in figure 14. Acceleration response of the open loop system was generated by applying 7 impulses during 18 seconds. Each response was decayed before the next was applied. This data was analyzed using the logarithmic decrement technique. The pitch mode damping ratio, $\zeta$, which is half of the structural damping, $g$, was determined to be .055 .

A similar test was performed to compare the open and closed loop behavior at zero airspeed without the plunge mode being constrained. The strain response to pluck tests of the open and closed loop systems were compared in figure 15 . Both responses were normalized such that the magnitude of the first peak was 1.0; the data were obtained using $20 \mathrm{~Hz}$ sample rates. From this plot, the damping is shown to have been increased by the presence of the controller.

\section{OPEN LOOP ELUTTER TESTING}

Flutter testing was conducted by placing the model in the wind tunnel at zero airspeed and then increasing the velocity. Data was taken for several minutes at various airspeeds. During this time interval the model sat at the tunnel condition. Flutter points were defined as the lowest airspeed at which the magnitude of the oscillations diverged within this time interval. The turbulence within the tunnel was relied upon to be sufficient to perturb the model. The increments in velocity were made smaller and data taken more frequently as the speed got near the predicted flutter value. Flutter was encountered experimentally at 580 inches per second. A time history 
of the strain gage during a run in which flutter was encountered, (figure 16), shows the divergent oscillations which begin growing at 4.5 seconds and continue to grow until the maximum possible amplitude was reached at 9.0 seconds. At this amplitude, safety stops of the tunnel inhibited the model's motion so that it wouldn't be destroyed. Frequency domain analysis, performed by taking fast Fourier transforms of the strain time history data indicates the flutter frequency of $9.4 \mathrm{~Hz}$.

\section{CLOSED LOOP TESTING}

Closed loop flutter testing was initiated by activating the control law at zero airspeed. Proceeding in the same manner as the open loop flutter testing, the speed was increased until flutter was encountered.

The closed loop data were compared with open loop data. Figure 17 shows time histories of the strain response for the two cases. These data were obtained just below the open loop flutter speed, at approximately 575 inches per second. The magnitude of the peaks for the closed loop case are decreased below the magnitudes of the open loop peaks. Due to limitations in the controller programming the controller update rate and data sampling must be consistent. The closed loop data was therefore obtained using a $20 \mathrm{~Hz}$ sample rate. This low sample rate is responsible for the spiky look of the graph.

The results of the flutter experiments and analyses are summarized in figure 18. The top graph of figure 18 shows the natural frequency variation as velocity is increased. Examining the zero airspeed data, the measured open loop values (7.9 and $11.1 \mathrm{~Hz}$ ) are slighty higher than the analytical predictions of these frequencies ( 7.8 and $10.9 \mathrm{~Hz})$. The higher frequency mode is the pitch mode; the lower frequency mode is the plunge mode. The analytical values for the two frequencies approach each other as the velocity increases. When frequencies coalesce, flutter generally onsets soon thereafter. The experimental open loop flutter frequency, $9.4 \mathrm{~Hz}$, is slightly larger than the frequency which the analysis predicted for flutter. The final point on this graph is the experimental closed loop flutter frequency, $9.7 \mathrm{~Hz}$.

The lower graph of figure 18 shows the damping ratio variation with velocity. Flutter is indicated on this graph by the damping ratio of one of the modes going to zero. Examining the zero airspeed data, the measured values of damping ratio (.017 and .055) were utilized in the analytical model. The analysis results are plotted over the velocity range until flutter occurs, (i.e. the lower mode crosses the zero damping axis), at $560 \mathrm{in} / \mathrm{sec}$. This value is $3.5 \%$ conservative as the experimental flutter speed was $580 \mathrm{in} / \mathrm{sec}$. The closed loop data at zero airspeed indicates that the control law provided an increase in the damping. Only the data for the plunge mode is presented. Analytical predictions of the damping behavior are presented over the entire velocity range, until closed loop flutter is predicted to occur at $648 \mathrm{in} / \mathrm{sec}$. The experimental value was $697 \mathrm{in} / \mathrm{sec}$. The predicted value is $7 \%$ conservative. Using single input/single output gain feedback, the flutter speed was predicted to improve by $15.7 \%$. The controller actually achieved an improvement of $20 \%$ of the flutter velocity.

\section{CONCLUSIONS \& RECOMMENDATIONS}

This research effort has resulted in the first experimental demonstration of flutter suppression employing piezoelectric actuators. A digital control law was designed and implemented based on a discretized model. Open and closed loop flutter tests were conducted, with excellent correlation achieved by analytical predictions. The open loop flutter velocity prediction was $3.5 \%$ conservative while the closed loop prediction was $7.6 \%$ conservative. The analysis indicated that the flutter velocity would be increased by $15.7 \%$ with the control law; a $20 \%$ improvement was observed experimentally.

It is recommended that further research be performed in the area of controlling the aeroelastic responses of a vehicle utilizing piezoelectric actuators. General areas which have yet to be tackled include buffet, gust, and maneuver load alleviation systems. Further vibration suppression research needs to be conducted using a more realistic and complex model which incorporates strain-actuating elements within a flexible wing design. The concept has been proven to work, however, it has not yet been shown to be workable in terms of real aircraft. Experiments on a larger scale are now called for.

\section{REEERENCES}

[1] Sandford, M.C., Abel, I., and Gray, D.L., Development and Demonstration of a Flutter Suppression System Using Active Controls, NASA TR R-450, December, 1975.

[2] Newsom, J.R., and Abel, I., Active Control of Aeroelastic Response, NASA TM-83179, July, 1981.

[3] Newsom, J.R., and Pototzky, A.S., Analysis and Flight Data for a Drone Aircraft with Active Fluter Suppression, Journal of Aircraft, Vol 19, Number 11, November 1982.

[4] Waszak, M.R., and Srinathkumar, S., Active

Flutter Suppression: Control System Design and Experimental Validation, AIAA Paper No. 91-2629, August 1991.

[5] Hwang, W.C., Demonstration of Active Wing I Store Flutter Suppression Systems, AFFDL TR-78-65, June 1980.

[6] Ehlers, S.M., Aeroelastic Behavior of an Adaptive Lifting Surface, PhD Dissertation, Purdue University, 1991.

[7] Weisshaar, T.A., and Ehlers, S.M., Adaptive Static and Dynamic Aeroelastic Design, Proceedings of the 1991 International Forum on Aeroelasticity and Structural Dynamics, Workshop on Smart Material 
Systerns and Structures, Aachen Deutschland, June 1991.

[8] Ehlers, S.M., and Weisshaar, T.A., Static

Aeroelastic Behavior of an Adaptive Laminated

Piezoelectric Composite Wing, Proceedings of the

AIAA/ASME/ASCE/AHS/ASC 31 st Structure, Structural

Dynamics, and Materials Conference, Part III pp 2340-

2350, Long Beach, CA, April 1990.

[9] Lazarus, K.B., Crawley, E.F., and Lin, C.Y., Fundamental Mechanisms of Aeroelastic Control with Control Surface and Strain Actuation, Proceedings of the AIAA/ASME/ASCE/AHS/ASC 32nd Structure, Structural Dynamics, and Materials Conference, Part III pp 1817-1831, Baltimore MD, April 1991.

[10] Scott, R.C., Control of Flutter Using Adaptive Materials, M.S. Thesis, Purdue University, May 1990.

[11] Heeg, J., An Analytical and Experimental Study to Investigate Flutter Suppression via Piezoelectric Actuation, M.S. Thesis, George Washington University, August 1991.

[12] Dunn, H.J., Experimental Results of Active Control on a Large Structure to Suppress Vibration, Proceedings AIAA GNC Conference, New Orleans, LA, 1991.

[13] Rodden, W.P., Giesing, J.P., and Kalman, T.P., New Developments and Applications of the Subsonic Doublet-Lattice Method for Nonplanar Configurations, AGARD Symposium on Unsteady Aerodynamics for Aeroelastic Analyses of Interfering Surfaces, Paper Number 4, November, 1970.

[14] Adams, W.H., Jr., Tiffany, S.H., Newsom, J.R., and Peele, E.L., STABCAR - A Program for Finding the Characteristic Roots of Systems Having Transcendental Stability Matrices, NASA TP 2165, June 1984.

[15] Tiffany, S.H., and Adams, W.M.Jr, Nonlinear Programming Extensions to Rational Function Approximation Methods for Unsteady Aerodynamic Forces, NASA Technical Paper 2776, July, 1988.

[16] Hoadley, S.T., and Silva W.A., User's Manual for the Interaction of Structures, Aerodynamics, and Controls Code, version 4.1, (to be published).

[17] MatrixX Release Notes, 7.0, Integrated Systems, Incorporated, October, 1988.

[18] Kuo, B.C., Digital Control Systems, Holt, Rinehart and Winston, Inc, 1980.

[19] Franklin, G.F., Powell, J.D., and Emani-Naeini, A., Feedback Control of Dynamic Systems, AddisonWesley Publishing Company, June 1986.

\begin{tabular}{c|c} 
Property & Value \\
\hline d $_{31}$ & $166 \times 10^{-12} \mathrm{~m} / \mathrm{V}$ \\
$\mathbf{d}_{33}$ & $-360 \times 10^{-12} \mathrm{~m} / \mathrm{V}$ \\
Maximum Voltage & $.7 \times 10^{6} \mathrm{v} / \mathrm{m}$ \\
Young's Modulus & $63 \times 10^{9} \mathrm{~N} / \mathrm{m}^{2}$ \\
$\begin{array}{c}.33 \\
\text { Poisson's Ratio } \\
\text { Density }\end{array}$ & $7.65 \times 10^{3} \mathrm{~kg} / \mathrm{m}^{3}$
\end{tabular}

Table 1 Material Properties for Lead Zirconate Titanate (PZT)

\begin{tabular}{l|l}
\multicolumn{1}{c|}{ PROPERTY } & VALUE \\
\hline Wing Mass & $.09 \mathrm{lbm}$ \\
Wing I $\alpha$ & $.134 \mathrm{lbm}-\mathrm{in2}$ \\
Wing Pitch Axis & $25 . \%$ chord \\
Wing Center of Gravity & $36.6 \%$ chord \\
Plunge Natural Frequency & $7.9 \mathrm{~Hz}$ \\
Pitch Natural Frequency & $11.1 \mathrm{~Hz}$ \\
Plunge Mode Structural Damping & .034 \\
Pitch Mode Structural Damping & .11
\end{tabular}

Table 2 Measured Model Characteristics 


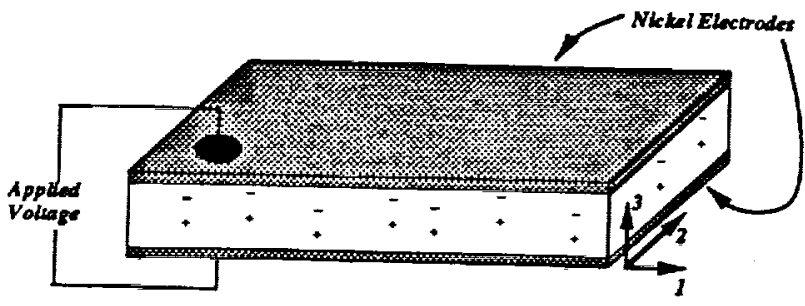

Fig. 1 Electrode placement on piezoelectric plate.

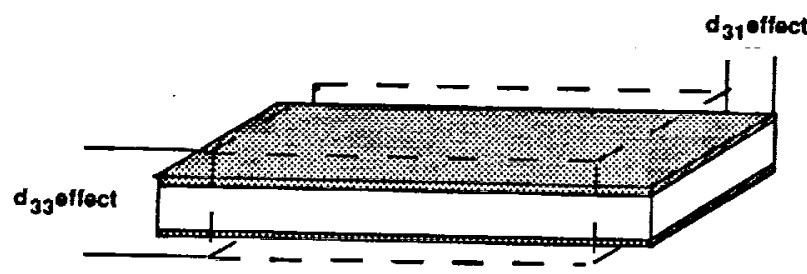

Fig. 2 Thickening $\left(d_{33}\right)$ and foreshortening $\left(d_{31}\right)$ effects of applied voltage.

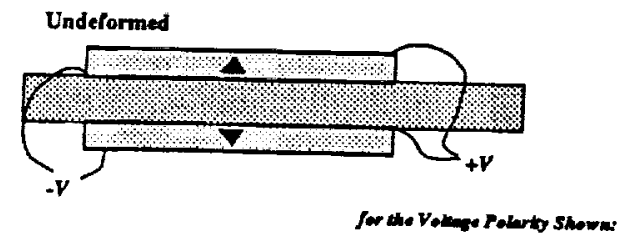

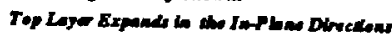

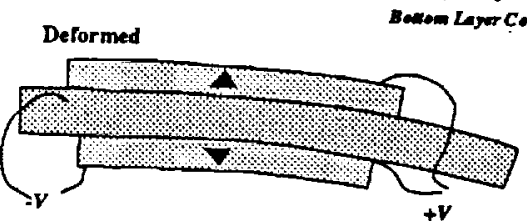

Fig. 3 Bimorph or Bender configuration of piezoelectric plate elements.

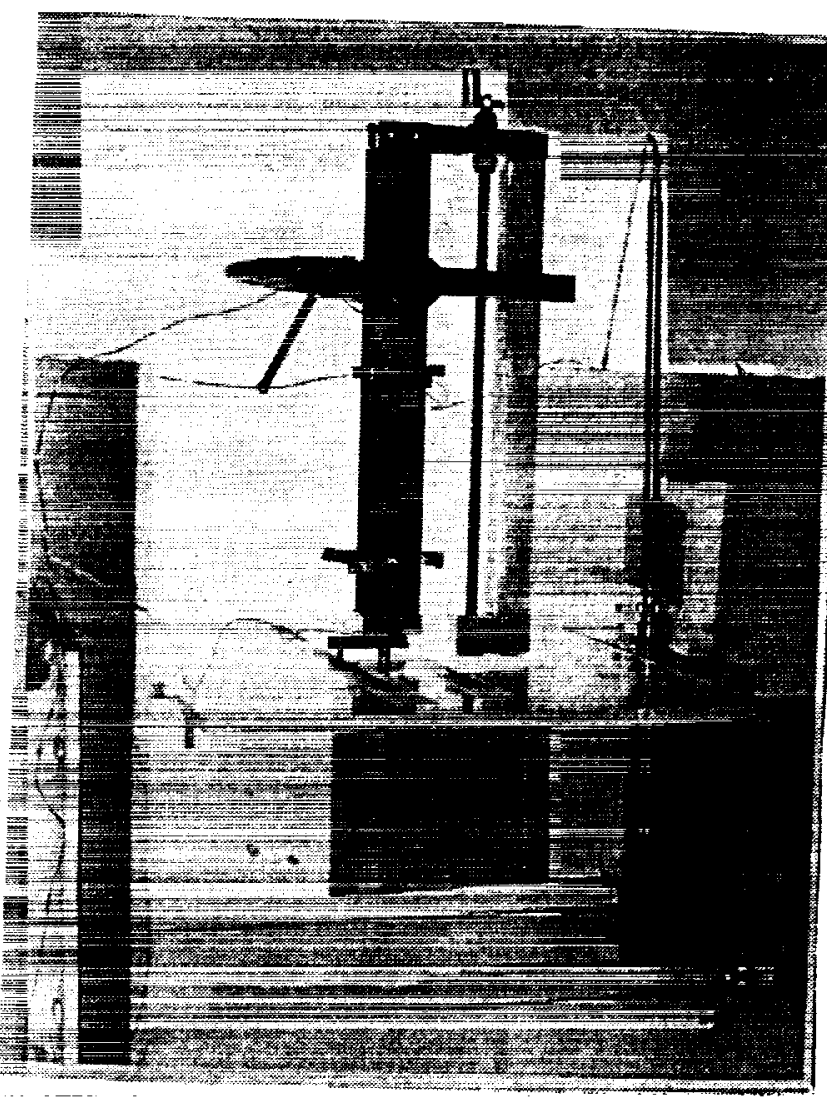

Fig. 4 Photograph of the test section with the wind-tunnel test article suspended from the ceiling.

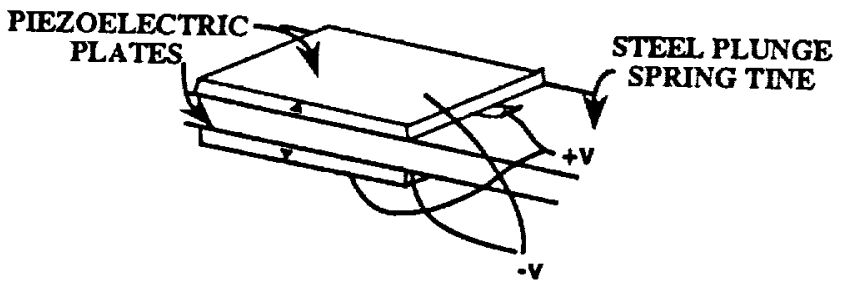

Fig. 5 Piezoelectric actuator attachment to plunge spring tine. 


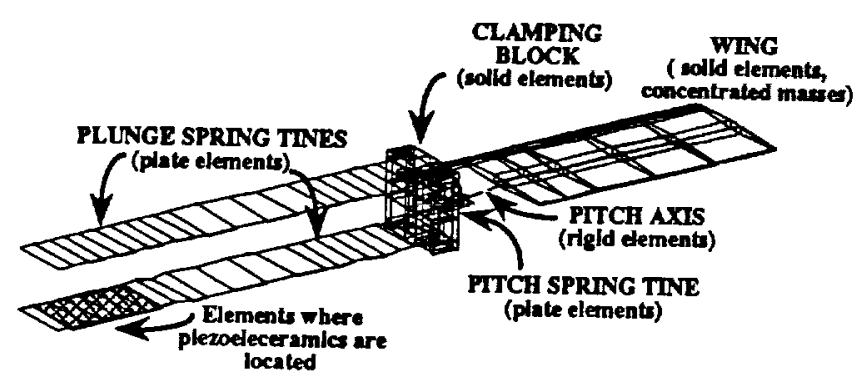

Fig. 6 Finite element model.

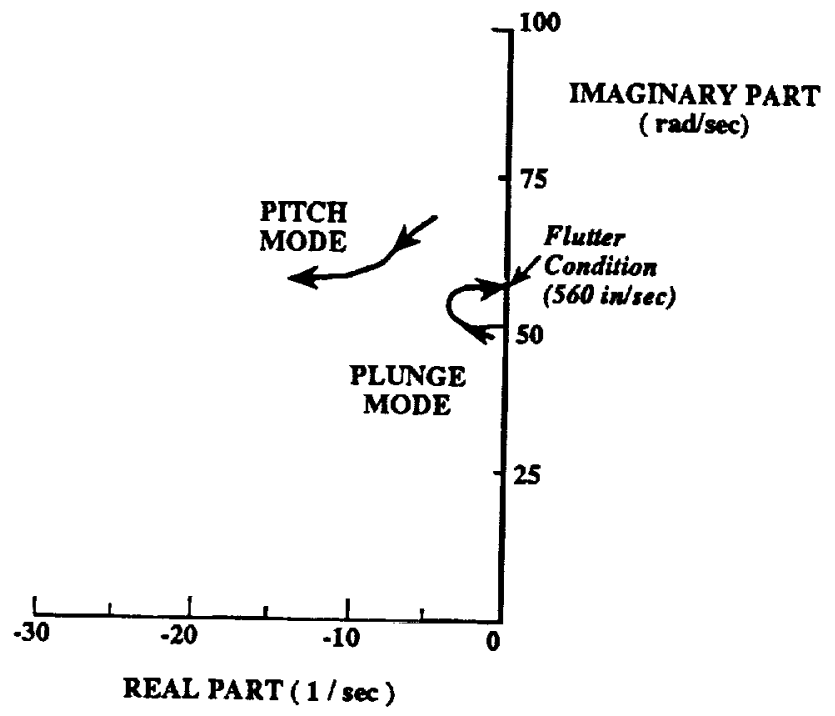

Fig. 7 Root locus-eigenvalue locations as velocity is varied.

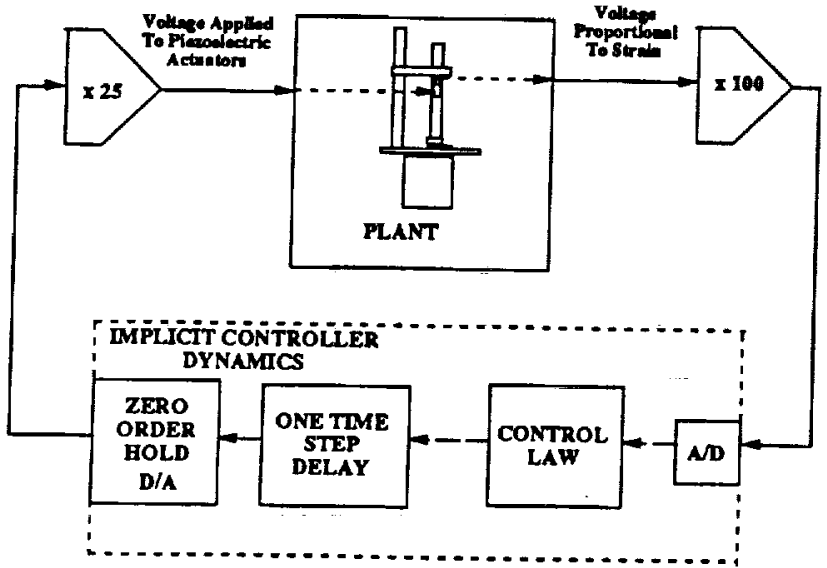

Fig. 8 Block diagram of closed-loop system.
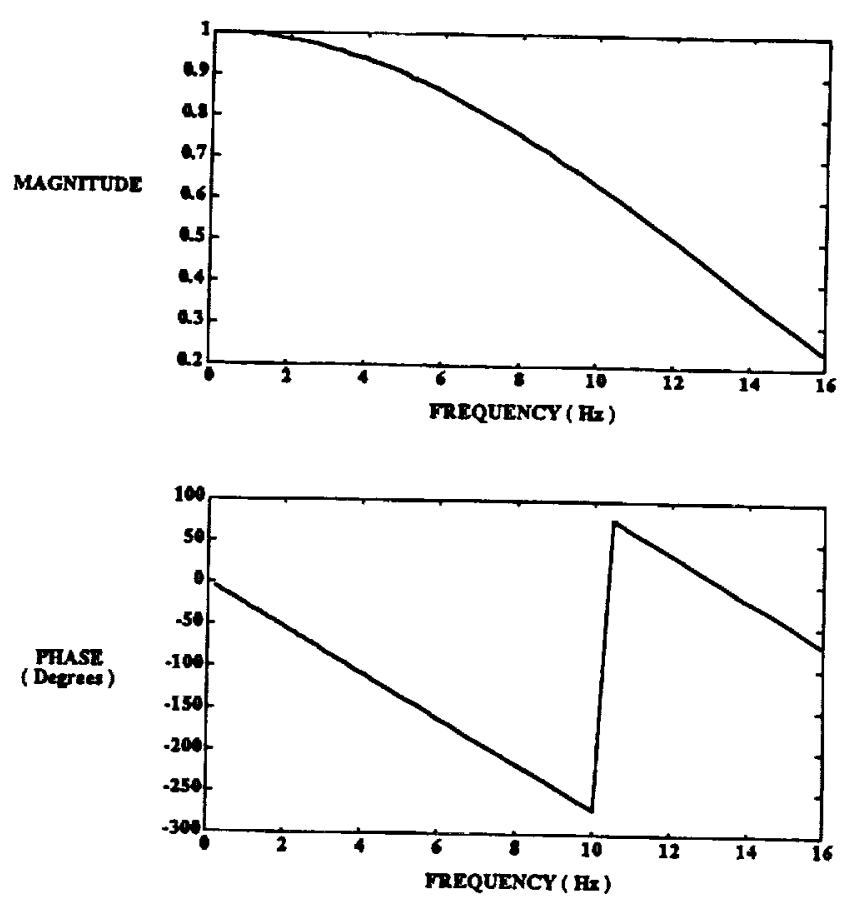

Fig. 9 Frequency response plot of implicit controller dynamics for $20 \mathrm{~Hz}$ sample rate (time delay and zero order hold).

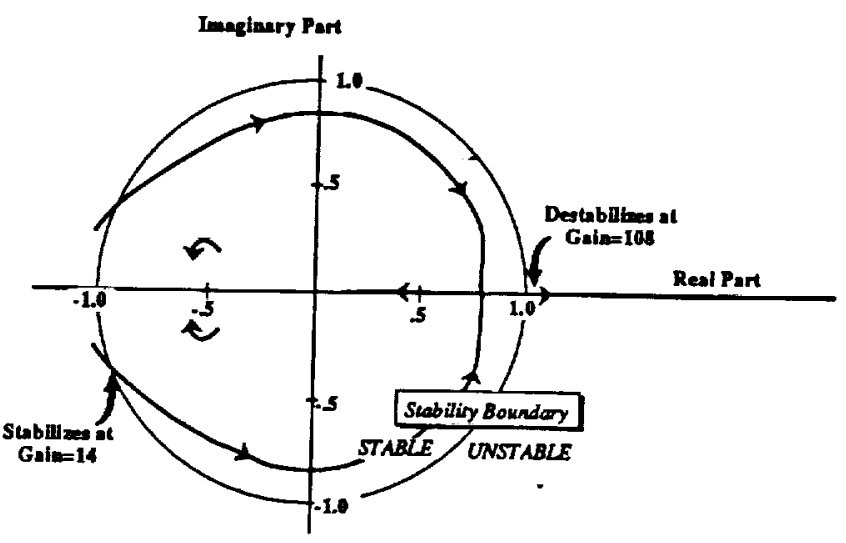

Fig. 10 Gain root locus of the discrete system at open loop flutter, 580 inches $/ \mathrm{sec}$ with gains from 0 to 120 . 

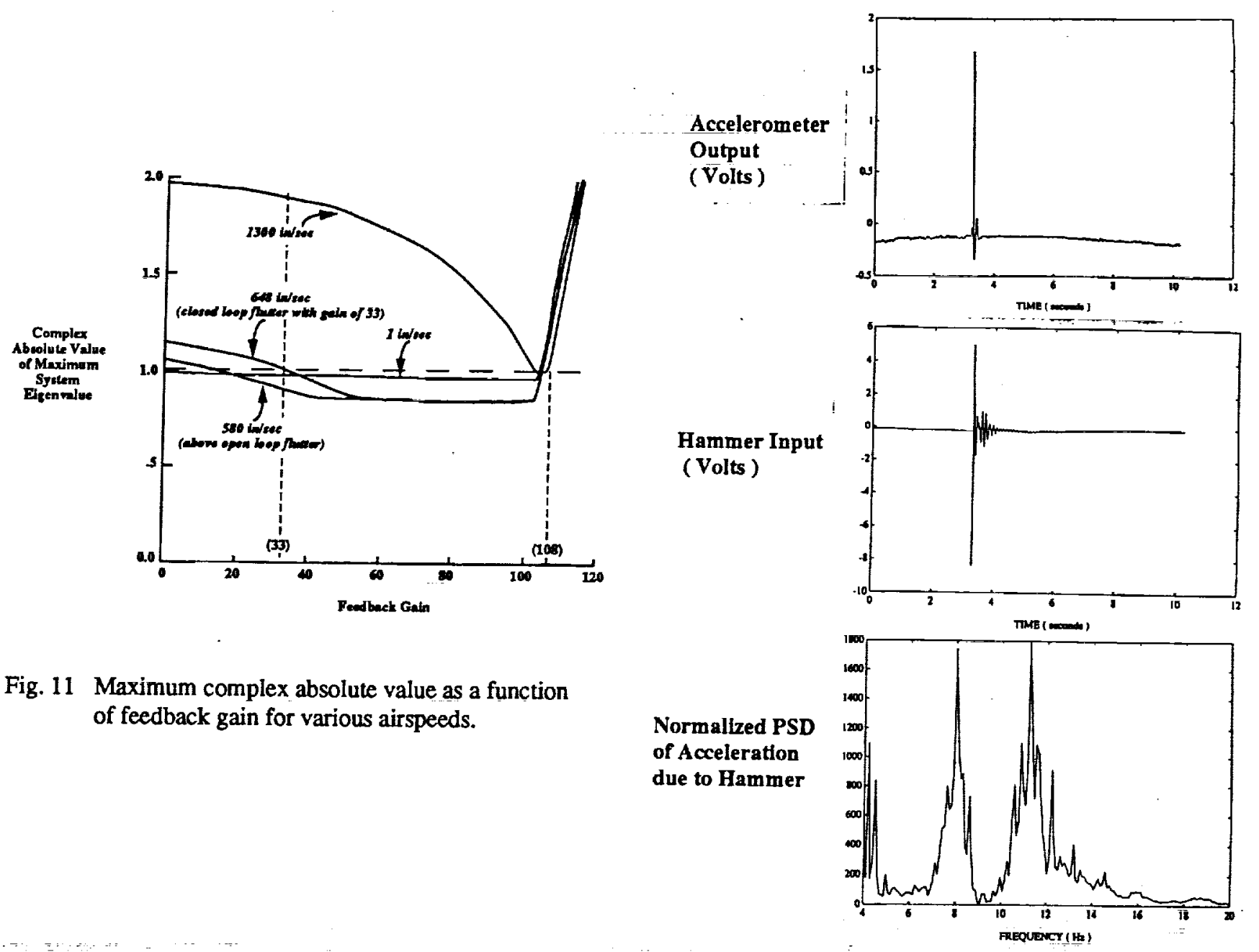

Fig. 11 Maximum complex absolute value as a function of feedback gain for various airspeeds.

Fig. 13 Results of impulsive input system identification tests.
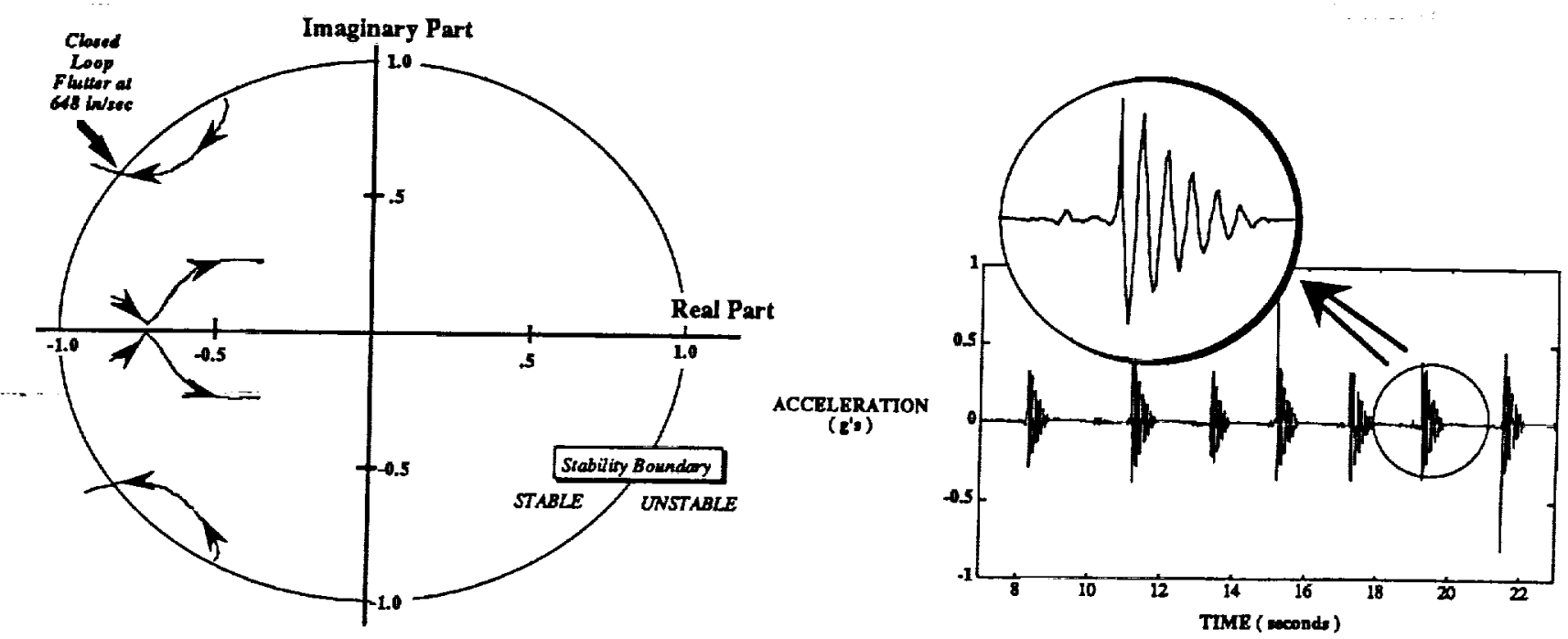

Fig. 12 Discrete system root locus for varying velocity of the closed loop system with feedback gain of 33 .

Fig. 14 Time history of acceleration response to plucks at zero airspeed (model constrained in plunge). 


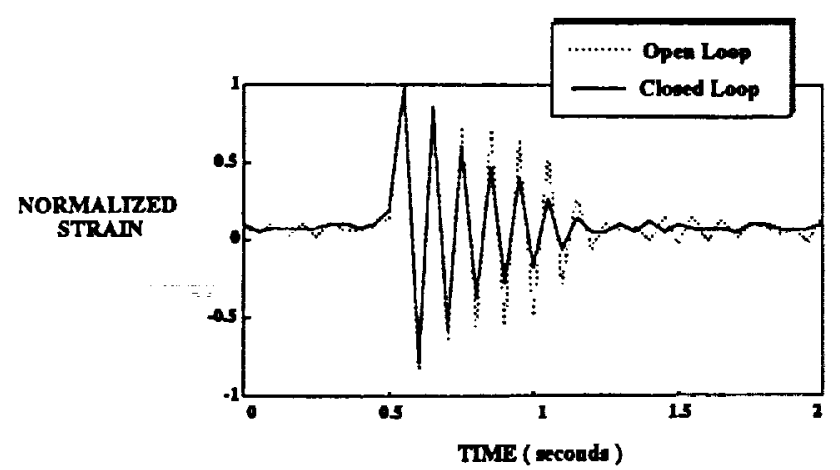

Fig. 15 Open and closed loop strain response to free decay test at zero airspeed.

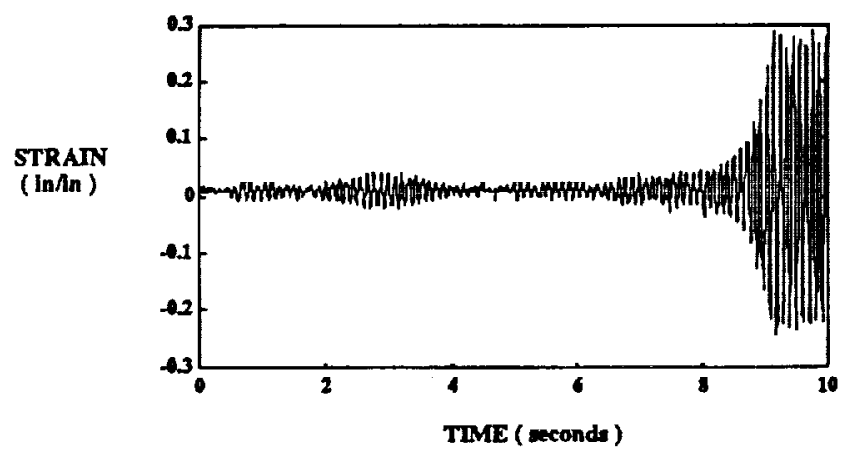

Fig. 16 Open loop flutter point, 580 inches per second.
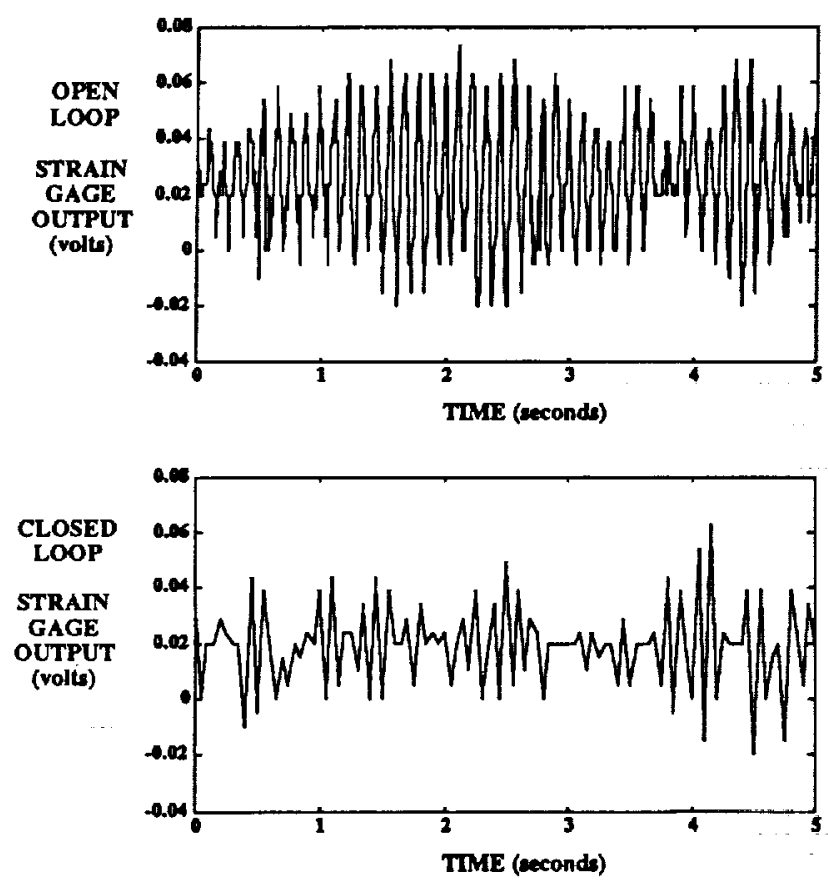

Fig. 17 Experimental open and closed loop strain response to wind tunnel turbulence just below flutter velocity ( 575 inches per second).

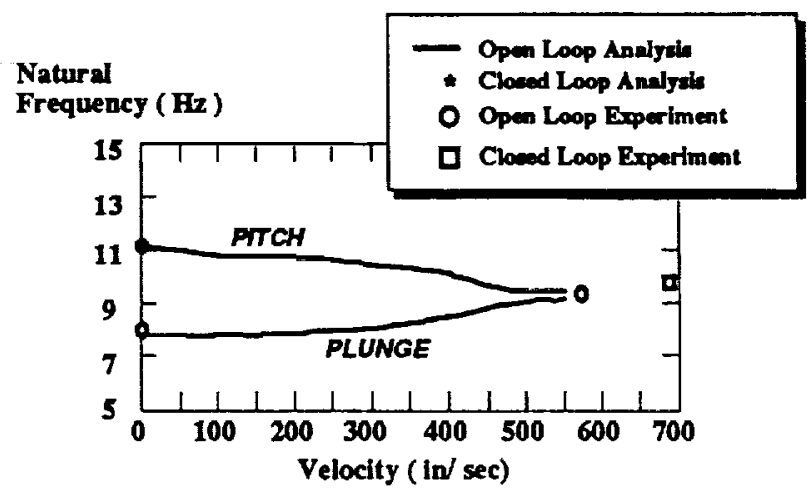

\section{Damping Ratio}

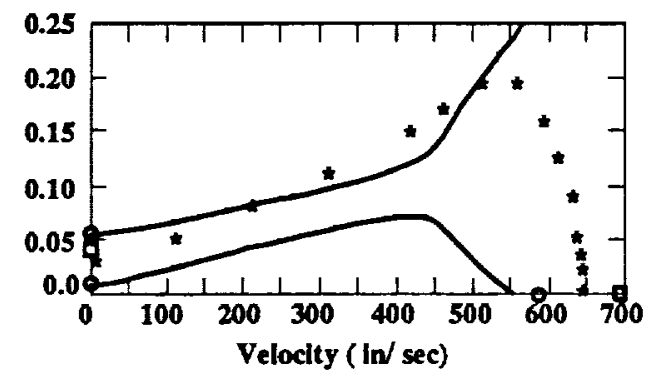

Fig. 18 Analytical and Experimental Flutter Results. 


\title{
REPORT DOCUMENTATION PAGE
}

Form Approved

OMB No. 0704-0188

Public reporting burden for this collection of information is estimated to average i hour per response, inciuding the time for reviewing instructions, searching extsting data sources, gathering and maintaining the data needed, and completing and reviewing the callection of information. Send comments regarding this burden estimate or any other aspect of this Devis Highway, Suite 1204. Arlington, VA 222024302 a (1)

\begin{tabular}{|l|c|c|c|}
\hline 1. AGENCY USE ONLY (Leave blank) & $\begin{array}{c}2 . \text { REPORT DATE } \\
\text { July } 1992\end{array}$ & $\begin{array}{c}\text { 3. REPORT TYPE AND DATES COVERED } \\
\text { Technical Memorandum }\end{array}$ \\
\hline
\end{tabular}

4. THLE AND SUBTITLE July 1992 Technical Memorandum

An Analytical and Experimental Investigation of Flutter Suppression Via Piezoelectric Actuation

WU 505-63-50-15

\author{
6. AUTHOR(5) \\ Jennifer Heeg
}

7. PERFORMING ORGANIZATION NAME(S) AND ADDRESS(ES)

NASA Langley Research Center

Hampton, VA $23665-5225$

8. PERFORMING ORGANIZATION REPORT NUMBER

9. SPONSORING/MONITORING AGENCY NAME(S) AND ADDRESS(ES)

10. SPONSORING / MONITORING AGENCY REPORT NUMBER

National Aeronautics and Space Administration

Washington, DC 20546-0001

NASA TM-107653

\section{SUPPLEMENTARY NOTES}

Presented at the AIAA 33rd Structures, Structural Dynamics, and Materials Conference, Dallas, Texas, April 13-15, 1992.

\author{
12a. DISTRIBUTION/AVALLABILITY STATEMENT \\ Unclassified - Unlimited \\ Subject Category 05
}

\section{ABSTRACT (Maximum 200 words)}

The objective of this research was to analytically and experimentally study the capabilities of adaptive material plate actuators for suppressing flutter. Piezoelectrics are materials which are characterized by their ability to produce voltage when subjected to a mechanical strain. The converse piezoelectric effect can be utilized to actuate a structure by applying a voltage. For this investigation, a two degree of freedom wind-tunnel model was designed, analyzed, and tested. The model consisted of a rigid wing and a flexible mount system which permitted translational and rotational degrees of freedom. Actuators, made of piezoelectric material were affixed to leaf springs of the mount system. Command signals, applied to the piezoelectric actuators, exerted control over the closed-loop damping and stiffness properties. A mathematical aeroservoelastic model was constructed using finite element methods, laminated plate theory, and aeroelastic analysis tools. Plant characteristics were determined from this model and verified by open-loop experimental tests. A flutter suppression control law was designed, implemented on a digital control computer, and tested to conditions 20-percent above the passive flutter speed of the model. The experimental results represent the first time that adaptive materials have been used to actively suppress flutter. It demonstrates that small, carefully-placed actuating plates can be used effectively to control aeroelastic response.

\begin{tabular}{|c|c|c|c|}
\hline \multicolumn{3}{|c|}{$\begin{array}{l}\text { 14. SUBJECT TERMS } \\
\text { Adaptive materials; aeroservoelasticity; flutter suppression } \\
\text { piezoelectricity }\end{array}$} & $\begin{array}{l}\text { 15. NUMBER OF PAGES } \\
12 \\
\end{array}$ \\
\hline $\begin{array}{l}\text { 17. SECURITY CLASSIFICATION } \\
\text { OF REPORT } \\
\text { Unclassified }\end{array}$ & $\begin{array}{l}\text { 18. SECURITY CLASSIFICATION } \\
\text { OF THIS PAGE } \\
\text { Unclassified }\end{array}$ & $\begin{array}{l}\text { 19. SECURITY CLASSIFICATION } \\
\text { OF ABSTRACT }\end{array}$ & 20. LIMITATION OF ABSTRACT \\
\hline
\end{tabular}

